\begin{tabular}{cl|l} 
Cellular Physiology & \multicolumn{1}{l}{\begin{tabular}{l} 
Cell Physiol Biochem 2012;30:321-333 \\
\cline { 2 - 3 } DOI: 10.1159/000339067
\end{tabular}} & $\begin{array}{l}\text { O 2012 S. Karger AG, Basel } \\
\text { www.karger.com/cpb }\end{array}$ \\
\hline & Published online: June 25, 2012 & $1015-8987 / 12 / 0302-0321 \$ 38.00 / 0$
\end{tabular}

\title{
Low-intensity Ultrasound Combined with 5-aminolevulinic Acid Administration in the Treatment of Human Tongue Squamous Carcinoma
}

\author{
Yanhong Lv ${ }^{1 \#}$ Ming Fang ${ }^{1 \#}$ Jinhua Zheng ${ }^{1,2^{\star}}$ Bing Yang ${ }^{2}$ Haixia $\mathrm{Li}^{1}$ Zhong \\ Xiuzigao $^{1}$ Wei Song ${ }^{2}$ Yan Chen ${ }^{1}$ Wenwu Cao ${ }^{2,3^{*}}$ \\ ${ }^{1}$ Department of Anatomy, Harbin Medical University, Harbin, ${ }^{2}$ Laboratory of Sono- and Photo- \\ Theranostic Technologies, Harbin Institute of Technologies, Harbin, ${ }^{3}$ Materials Research Institute, \\ Pennsylvania State University, University Park, Pennsylvania, \#,*Both Authors contributed equally to this \\ work
}

\section{Key Words}

Ultrasound therapy - 5-aminolevulinic acid - Human tongue squamous carcinoma • Mitochondrial apoptotic pathway • Reactive oxygen species • Intracellular $\mathrm{Ca}^{2+}$

\begin{abstract}
We investigated the anti-tumor efficiency of sonodynamic therapy (SDT) on human tongue squamous carcinoma SAS cell line using low intensity ultrasound (LIU) of 0.6 and $0.8 \mathrm{~W} / \mathrm{cm}^{2}$, plus 5-aminolevulinic acid (ALA). Xenograft in vivo experiments using Balb/ca nude mice and MTT assays in vitro showed that ALA-LIU therapy significantly suppressed the proliferation of SAS cells. ALA-LIU therapy markedly enhanced SAS cell apoptosis rate compared to LIU alone. Based on TEM and fluorescence microscopy observations, there are notably morphology changes and seriously swollen mitochondria in xenograft tissues, and ALA-induced PpIX bond strongly to mitochondria of SAS cells. Immunohistochemical staining and western blotting demonstrated upregulation of Bax, cytochrome $\mathrm{c}$ and caspase-3, and downregulation of $\mathrm{Bcl}-2$ for both in vivo and in vitro cases after ALA-LIU treatment. Increase of reactive oxygen species (ROS) in the ALA-LIU treatment groups were found using 2, 7-dichlorofluorescin diacetate (DCFH-DA) staining. Administration of the ROS scavenger, $\mathrm{N}$-acetylcysteine (NAC), suppressed ALA-LIU-induced apoptosis and the expression of mitochondria apoptosis-related proteins, which confirmed that the ALA-LIU induced SAS cell apoptosis is through the generation of ROS. The process initially damaged mitochondria, activated pro-apoptotic factors Bax and cytochrome $\mathrm{c}$ and supressed the anti-apoptotic factor Bcl-2, activated caspase- 3 to executed apoptosis through mitochondrial signaling pathway.
\end{abstract}

Copyright $\odot 2012$ S. Karger AG, Basel 


\section{Cellular Physiology $\quad$ Cell Physiol Biochem 2012;30:321-333 \begin{tabular}{ll|l} 
and BiOchemistry & $\begin{array}{l}\text { DOI: 10.1159/000339067 } \\
\text { Published online: June 25, 2012 }\end{array}$ & $\begin{array}{l}\text { C) 2012 S. Karger AG, Basel } \\
\text { www.karger.com/cpb }\end{array}$ \\
\cline { 2 - 3 } & Lv/Fang/Zheng et al.: Low-intensity Ultrasound and 5-aminolevulinic Acid Therapy on
\end{tabular} Tongue Carcinoma}

\section{Introduction}

Tongue cancer ranks as the most malignant of oral cavity cancers, characterised by rapidly growing tumours. Traditional surgical excision causes facial disfigurement, difficulties in chewing and swallowing, and dysphasia, while concurrent chemotherapy and radiotherapy also give rise to side effects in patients with poor prognosis [1]. Sonodynamic therapy (SDT) is a novel non-invasive intervention strategy for tumour treatment, whose anti-tumour activity arises from the synergistic effects from the combined application of low-intensity ultrasound (LIU) and sonosensitisation. This procedure selectively kills local primary and recurrent tumour cells by utilising the targeting ability of the sonsensitiser and the localisation ability of ultrasound energy. Thus, SDT can effectively target and inhibit the growth of various cancer cell types in vitro and in vivo [2-7].

Many investigators believe that apoptosis plays a vital role in the anti-cancer effect of SDT $[4,8-12]$. It is widely accepted that ultrasound activate sonosensitisers to produce cytotoxic reactive oxygen species (ROS) such as singlet oxygen $\left(\mathrm{O}^{2-}\right)$, which can destroy cells on contact $[8,9,12]$. Furthermore, the activities of various key anti-oxidases, including superoxide dismutase (SOD) and haeme oxygenase (HO)-1, are weakened by SDT [13, 14], suggesting the importance of oxidative stress in cellular apoptosis induced by ultrasound or SDT. The most commonly used sonosensitisers, haematoporphyrin (Hp) and their derivatives, selectively accumulate on tumour sites, and within a few hours, they are rapidly excreted from the body with little residual cellular toxicity. The sub-cellular localisation of the sonosensitiser, such as cell membranes and mitochondria, was typically identified as the sites of cellular damage by ultrasound. Endogenous protoporphyrin IX (PpIX), but not exogenous PpIX, converted from the 5-aminolevulinic acid (5-ALA) mainly accumulated in the mitochondria [15].

High-intensity focused ultrasound (HIFU) has already been in clinical use for the treatment of tumours, with an effectiveness that has been confirmed by clinical research [16]. However, HIFU has a limited treatment volume, and may cause overheating of normal surrounding tissues. More importantly, it primarily induces cell necrosis, which may cause an unpredictable immune response and trigger metastasis. Non-thermal LIU may assist in the treatment of tumours by suppressing the mitosis of cancer cells, but LIU alone could also trigger the proliferation of malignant cells, contributing to metastasis [17].

The effectiveness of low intensity ultrasound is related to its promotion of non-thermal effects, including mechanical and indirect chemical effects, which result in tumour inhibition $[18,19]$. In a previous study, we showed that ALA combined with LIU acted synergistically to cause damage to and apoptosis of SAS cells in vitro. Excessive intracellular ROS production induced by ALA-LIU, followed by an increase in lipid peroxidation (LPO) and a decrease in mitochondrial membrane potential (MMP), were primarily responsible for the significantly higher cell apoptosis rates compared with the use of LIU alone [20]. In this study, we assess the inhibitory effect of ALA-LIU on human tongue squamous carcinoma in Balb/ca nude mice and in SAS cells. The focus of our attention is oxidative stress in mitochondria and intracellular $\mathrm{Ca}^{2+}$-mediated apoptosis pathways in ALA-LIU-induced apoptosis.

\section{Materials and Methods}

Tumour model and localisation of 5-ALA converted PPIX in vivo and in vitro

Male Balb/ca nude mice (SLAC; Shanghai Laboratory Animal Center, Shanghai, China) were housed in dedicated, pathogen-free barrier facilities. A $0.2 \mathrm{~mL}$ suspensions of tongue squamous carcinoma SAS cells (Human Science Research Resources Bank, Osaka, Japan) at a density of $1 \times 10^{5}$ cells $/ \mathrm{mL}$ in serum-free medium were subcutaneously (s.c.) injected into the right-hand flanks of four-week-old mice. Following tumour formation, the mice were intravenously (i.v.) injected with $250 \mathrm{mg} / \mathrm{kg}$ of 5-ALA (Sigma Chemicals, St. Louis, MO, USA) solution. The distribution of 5-ALA-endogenous PpIX in mice was measured every $2 \mathrm{~h}$ through the red fluorescence intensity of PpIX under the excitation supplied by a 405-nm blue light source. 


\section{Cellular Physiology Cell Physiol Biochem 2012;30:321-333 \begin{tabular}{ll|l} 
and BiOChemistry & $\begin{array}{l}\text { DOI: 10.1159/000339067 } \\
\text { Published online: June 25, } 2012\end{array}$ & $\begin{array}{l}\text { C } 2012 \text { S. Karger AG, Basel } \\
\text { www.karger.com/cpb }\end{array}$ \\
$\begin{array}{l}\text { Lv/Fang/Zheng et al.: Low-intensity Ultrasound and 5-aminolevulinic Acid Therapy on } \\
\text { Tongue Carcinoma }\end{array}$
\end{tabular}}

Cells were seeded in six-well plates and incubated with serum-free RPMI 1640 medium containing 10 $\mu \mathrm{g} / \mathrm{mL}$ 5-ALA for $4 \mathrm{~h}$, re-suspended in phosphate-buffered saline (PBS), and co-stained with $10 \mu \mathrm{g} / \mathrm{mL} \mathrm{of}$ rhodamine 123 (Sigma Chemicals, St. Louis, MO, USA) for $10 \mathrm{~min}$. After washing twice with PBS, the cells were observed under a fluorescence microscope for the sub-cellular localisation patterns.

\section{Sonication device and treatment protocol in vivo and in vitro}

The ultrasonic generator and power amplifier used in this study was assembled by Harbin Institute of Technology (Harbin, China), as shown in Figure 1A. Murine tumours were immersed in degassed water, and placed directly in line with the center of ultrasonic transducer (diameter: $2.5 \mathrm{~cm}$; centre frequency: 1.0 MHz; duty factor: $10 \%$; repetition frequency: $100 \mathrm{~Hz}$ ) surface at a distance of $15 \mathrm{~cm}$, to ensure field uniformity. The internal surface of the glass tank was padded with ultrasound-absorbing materials to minimise reflection waves. The ultrasonic intensity used was $0.8 \mathrm{~W} / \mathrm{cm}^{2}$, as measured inside the tank by using a hydrophone (Onda Corp., Sunnyvale, CA, USA). The temperature of the water was maintained at $25^{\circ} \mathrm{C}$ $\pm 2^{\circ} \mathrm{C}$ during the sonication. When the tumours had grown to a diameter of 5-7 mm within approximately 10 days of implantation, the animals were randomly divided into six groups to undergo varying treatments: the control group (C), $250 \mathrm{mg} / \mathrm{kg}$ of 5-ALA solution alone (A), sonication alone - twice (Us $)_{2}$ ), sonication - once plus 5-ALA $\left(\mathrm{AUs}_{1}\right)$, sonication - twice plus 5-ALA $\left(\mathrm{AUs}_{2}\right)$, and sonication - thrice plus 5-ALA (AUs ${ }_{3}$ ). Ultrasound radiation was applied for $15 \mathrm{~min}$ at each treatment, and the interval between treatments was 6 $\mathrm{h}$. Sonication began at $12 \mathrm{~h}$ after injection with 5-ALA solution in the sonication plus 5-ALA groups.

In the in vitro experiments, the cells were sealed in a suspension bag inside a water tank, and positioned $9 \mathrm{~cm}$ from the transducer surface to utilise the far field for uniformity. The ultrasound frequency was 0.87 $\mathrm{MHz}$, provided in a pulse wave mode with a duty factor of $60 \%$ and a repetition frequency of $100 \mathrm{~Hz}$; ultrasonic intensity at this position was $0.6 \mathrm{~W} / \mathrm{cm}^{2}$, as measured by a hydrophone. The SAS cell suspension was divided into eight groups: control (C), 5-ALA alone (A), sonication - 1 min $\left(U_{1}\right)$, sonication -3 min $\left(U_{2}\right)$, sonication - 5 min $\left(U_{3}\right)$, sonication - 1 min plus 5-ALA $\left(A U_{1}\right)$, sonication - 3 min plus 5-ALA $\left(A_{2}\right)$, and sonication - 5 min plus 5-ALA $\left(\mathrm{AU}_{3}\right)$. For the A and AU groups, the cell suspensions were mixed with 10 $\mu \mathrm{g} / \mathrm{mL} 5$-ALA solution, and incubated for $4 \mathrm{~h}$ in the dark. For the $\mathrm{U}$ and $\mathrm{AU}$ groups, the cell suspensions were placed in small PE bags $(1.5 \times 2.0 \mathrm{~cm})$ and sonicated at $37^{\circ} \mathrm{C}$ in the dark.

\section{Evaluation of anti-tumour effect}

The long and short diameters ( $\mathrm{a}$ and $\mathrm{b}$, in millimeters, respectively) of the tumours were measured daily with a slide caliper after the treatments. Tumour volumes were calculated according to the formula $\left[(\pi / 6) \mathrm{a} \times \mathrm{b}^{2}\right]$. All mice were sacrificed 10 days after drug administration.

\section{Transmission electron microscopy}

Xenografts were dissected and fixed with $2.5 \%$ glutaraldehyde for $2 \mathrm{~h}$, post-fixed in $1 \%$ osmium tetroxide (Os04) at $4^{\circ} \mathrm{C}$ for $2 \mathrm{~h}$, and embedded with Epon 812 for $72 \mathrm{~h}$ at $60^{\circ} \mathrm{C}$. Ultra-thin sections were cut and stained with uranium acetate, followed by lead citrate, and then observed under a transmission electron microscope (Hitachi, Tokyo, Japan).

\section{TUNEL assay for apoptotic cells in vivo}

Apoptosis was assessed in xenograft tumours by using the terminal deoxyribonucleotide transferasemediated nick-end labelling (TUNEL) method in combination with an in situ apoptotic detection kit (Boster Biological Technology, Ltd., Wuhan, China), according to the manufacturer's instructions, and stained with diaminobenzene (DAB) for $10 \mathrm{~min}$. Slides were examined using a polarised light microscope (Nikon, Tokyo, Japan).

\section{Immunohistochemical staining}

Tumours were harvested, fixed in $4 \%$ paraformaldehyde (PFA), dehydrated with a graded ethanol series, cleared in dimethylbenzene, and embedded in paraffin. Next, tissue blocks were cut into $4-\mu \mathrm{m}$ sections by using a paraffin-slicing machine (Leica, Nussloch, Germany), and mounted on glass slides. Tissue sections were deparaffinised and rehydrated, heated in citrate buffer $(0.01 \mathrm{M}, \mathrm{pH} 6.0)$, and treated with endogenous peroxidase at room temperature. After blocking in $10 \%$ goat serum, the sections were stained with rabbit polyclonal anti-Bcl-2 (1:200; Santa Cruz Biotechnology, Inc., CA, USA), mouse monoclonal anti-caspase-3 (1:200; Santa Cruz Biotechnology, Inc.), rabbit polyclonal anti-Bax (1:200; Santa Cruz Biotechnology, Inc.), 


\section{Cellular Physiolosy Cell Physiol Biochem 2012;30:321-333 \begin{tabular}{ll|l}
\cline { 2 - 2 } and Biochemistry & $\begin{array}{l}\text { DOI: 10.1159/000339067 } \\
\text { Published online: June 25, 2012 }\end{array}$ & $\begin{array}{l}\text { C 2012 S. Karger AG, Basel } \\
\text { www.karger.com/cpb }\end{array}$ \\
\cline { 2 - 3 } & $\begin{array}{l}\text { Lv/Fang/Zheng et al.: Low-intensity Ultrasound and 5-aminolevulinic Acid Therapy on } \\
\text { Tongue Carcinoma }\end{array}$
\end{tabular}}

or rabbit polyclonal anti-cytochrome c (1:300; Boster Biological Technology, Ltd.) primary antibodies and incubated overnight at $4^{\circ} \mathrm{C}$. Subsequently, sections were incubated with secondary antibodies and stained with DAB reagent. Finally, all sections were observed under an electron microscope. Immunopositive expression in cells was quantified with integrated optical density (IOD) values by using Image Pro Plus (IPP) software 6.0 (Media Cybernetics, Inc., Bethesda, MD, USA).

All animal experiments strictly followed the guidelines of the Laboratory Animal Committee of the Harbin Medical University.

\section{Assessment of cell viability in vitro}

After various treatments, cells were re-incubated in 96-well plates for 1, 2, 4, 6, and $12 \mathrm{~h}$. Cell viability was measured using MTT cell proliferation assays and a Cytotoxicity Detection Kit (KeyGen Biotech, Nanjing, China). The absorbance value (AV) was measured at $570 \mathrm{~nm}$ by using a microplate reader (Awareness Technology Inc., Burlington, VT, USA). The percentage of cell viability was calculated using the following formula: (AV of experiment well/AV of control well) $\times 100 \%$.

\section{Cell apoptosis analysis}

An annexin V-PI apoptosis detection kit (KeyGen Biotech) was used for apoptosis analysis. The treated and control cells were harvested, and washed three times with PBS at $4^{\circ} \mathrm{C}$. Annexin V $(5 \mu \mathrm{L})$ and propidium iodide or PI ( $5 \mu \mathrm{L})$ were added to $490 \mu \mathrm{L}$ of suspension, and mixed gently. After incubation at $4^{\circ} \mathrm{C}$ for $30 \mathrm{~min}$ in the dark, the cells were observed under a fluorescence microscope (Olympus, Tokyo, Japan) and counted by a flow cytometer (FACSCount, NY, USA).

\section{Immunoblotting}

Cells were lysed in RIPA buffer (Beyotime Biotechnology Inc., Nantong, China) on ice. Protein concentrations were determined using a BCA Protein Assay Kit (Beyotime Biotechnology Inc.). Cell lysates ( $50 \mu$ g of protein) were separated by $10 \%$ SDS-PAGE, and electrophoretically transferred onto polyvinylidene fluoride membranes. After blocking in TBS-T containing $5 \%$ low-fat milk, the membranes were incubated overnight at $4{ }^{\circ} \mathrm{C}$ with primary antibodies against the target proteins Bcl-2 (1:200), Bax (1:200), cytochrome c (1:200), caspase-3 (1:200), with $\beta$-actin as a loading control. After washing twice with TBS-T, the membranes were incubated with secondary anti-rabbit IgG antibody linked to horseradish peroxidase, and protein levels were detected using an ECL detection system (Amersham, Uppsala, Sweden).

\section{Measurement of intracellular ROS}

Intracellular ROS levels were determined by detecting the fluorescence of 2, 7-dichlorofluorescein (DCF) by using a ROS assay kit (Applygen, Beijing, China). After treatment, cells were plated onto cover-slips in 12-well plates in serum-free dichlorofluorescin diacetate (DCFH-DA, $10 \mu \mathrm{M}$ ) at $37^{\circ} \mathrm{C}$ for $20 \mathrm{~min}$ in the dark. Cover-slips were rinsed three times in PBS, and then mounted onto glass for microscopic observation. The level of intracellular ROS was determined by the fluorescent intensity quantified with IOD values.

In experiments involving the ROS scavenger N-acetylcysteine (NAC), the cells were pre-treated with 10 mM NAC (Beyotime Biotechnology Inc.), immediately followed by ultrasound exposure.

\section{Intracellular $\mathrm{Ca}^{2+}$ concentration assay}

Intracellular $\mathrm{Ca}^{2+}$ concentration $\left(\left[\mathrm{Ca}^{2+}\right] \mathrm{i}\right)$ was measured using the fluorescent $\mathrm{Ca}^{2+}$ probe fura-2 $\mathrm{AM}$ (Beyotime Biotechnology Inc.). After treatment, cells were incubated with $4 \mu \mathrm{M}$ fluo-2 $\mathrm{AM}$ at $37^{\circ} \mathrm{C}$ for 30 min in the dark, and gently rinsed twice with D-Hanks' solution. Fura-2 fluorescence was observed under a fluorescence microscope. Fluorescence intensity was determined using a Cary Eclipse Spectrophotometer (Varian, Madrid, Spain) with excitation and emission wavelengths of $340 \mathrm{~nm}$ (or $380 \mathrm{~nm}$ ) and $510 \mathrm{~nm}$, respectively. The $\left[\mathrm{Ca}^{2+}\right] \mathrm{i}$ was estimated by the $340 / 380$-ratio method, by using a Kd value of $224 \mathrm{nM}$.

\section{Statistical analysis}

All data are shown as the mean \pm standard deviation (SD) values. The difference between groups was analysed according to Student's $t$-test. Statistical evaluation was performed using SPSS 13.0 software. Differences were considered statistically significant at $P<0.05$. 


\section{Cellular Physiology Cell Physiol Biochem 2012;30:321-333 \begin{tabular}{ll|l}
\cline { 3 - 3 } and Biochemistry & $\begin{array}{l}\text { DOI: 10.1159/000339067 } \\
\text { Published online: June 25, } 2012\end{array}$ & $\begin{array}{l}\text { C 2012 S. Karger AG, Basel } \\
\text { www.karger.com/cpb }\end{array}$ \\
\cline { 2 - 3 } & Lv/Fang/Zheng et al.: Low-intensity Ultrasound and 5-aminolevulinic Acid Therapy on
\end{tabular} Tongue Carcinoma}

Fig. 1. Ultrasound setup in vivo and distribution of ALAinduced PpIX in mice. (A) Ultrasound exposure system for the treatment of nude mice xenograft. (B) Images of distribution of ALA-induced PpIX in mice at $12 \mathrm{~h}$ and $24 \mathrm{~h}$. The red colour is PpIX at the site of the tumour.

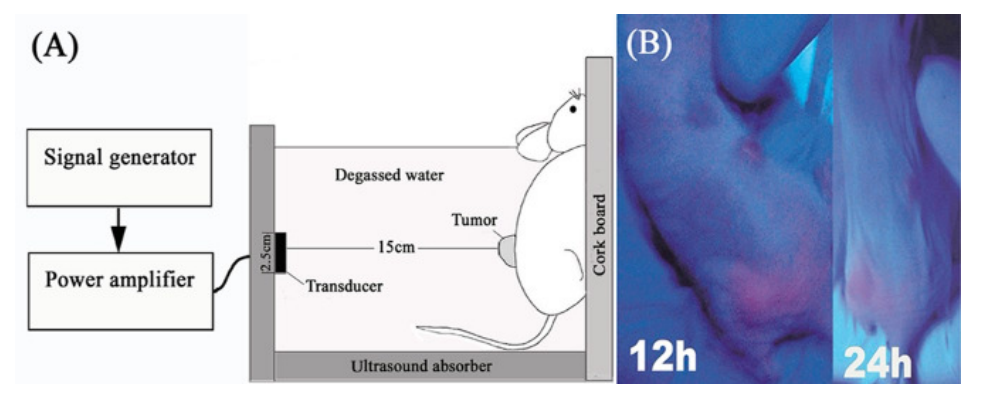

(A)

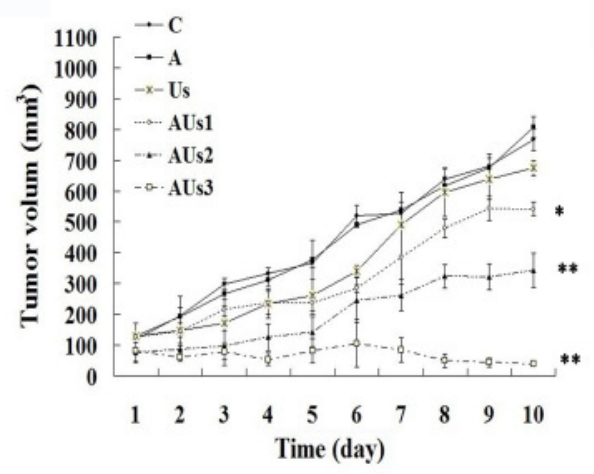

(B)

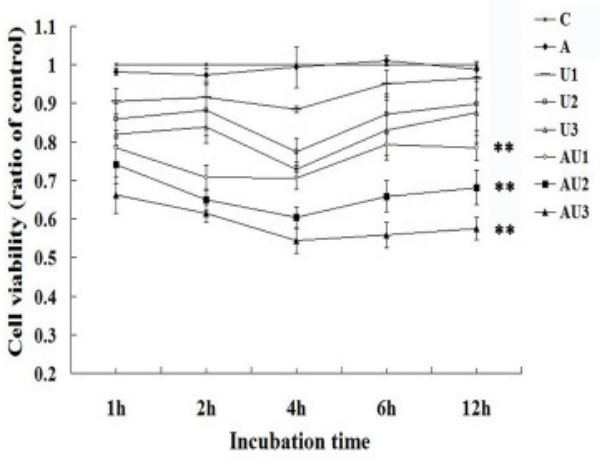

Fig. 2. Inhibition of growth of SAS cells in vivo and in vitro. (A) Average tumour volume observed after different treatments. Error bars represent the SD $(n=3)$. ${ }^{*} p<0.05$ and ${ }^{* *} p<0.01$ vs. C or A group. (B) Cell proliferation effect of different treatments, as tested by MTT assay. Cell viability was presented as a percentage of AV570 relative to the control group and is represented as the mean \pm SD value of three experiments. ${ }^{* *} \mathrm{p}<0.01$ vs. $\mathrm{C}$ or A group.

\section{Results}

Protoporphyrin IX produced by metabolism of 5-ALA in vivo was localised to tumour sites

To observe the aggregation of endogenous PpIX in tongue cancer xenografts, mice were illuminated every $2 \mathrm{~h}$ with a 405-nm blue light source after the injection of 5-ALA solution. The results showed that the red fluorescence of PpIX concentrated in the tumour sites; the intensity was the strongest at $12 \mathrm{~h}$ after injection, and had practically diminished by $24 \mathrm{~h}$ (Fig. 1B). Therefore, the ultrasound treatment time was chosen as $12 \mathrm{~h}$ after 5-ALA administration for future experiments.

\section{ALA-LIU significantly suppressed the proliferation of human tongue squamous carcinoma}

SAS cells in vivo and in vitro

The anti-tumour efficacy of ALA-LIU was evaluated in vivo. Tumour growth in different treatment groups was evaluated by measuring tumour volumes. As shown in Figure 2A, tumour growth remained unchanged compared with the controls when the tumours were treated with 5-ALA alone. Sonication alone resulted in some degree of anti-tumour activity, becoming weaker with time post-treatment, and there was no significant difference in the growth rate compared with the control group on day 8. However, ultrasound combined with 5-ALA substantially inhibited tumour growth, and the effect was noticeably enhanced with an increase in ultrasound treatment time.

The survival rate of SAS cells under different treatment regimens was detected by MTT assays in vitro. As shown in Figure 2B, both ultrasound alone and in combination with 5-ALA suppressed cellular proliferation during the same treatment interval, and the cell viability 


\section{Cellular Physiology $\quad$ Cell Physiol Biochem 2012;30:321-333 \begin{tabular}{ll|l}
\cline { 3 - 3 } and Biochemistry & DOI 10.1159/000339067 & $\begin{array}{l}\text { C 2012 S. Karger AG, Basel } \\
\text { www.karger.com/cpb }\end{array}$ \\
\cline { 2 - 3 } & Published online: June 25, 2012 & Lv/Fang/Zheng et al.: Low-intensity Ultrasound and 5-aminolevulinic Acid Therapy on
\end{tabular} Lv/Fang/Zheng et
Tongue Carcinoma}

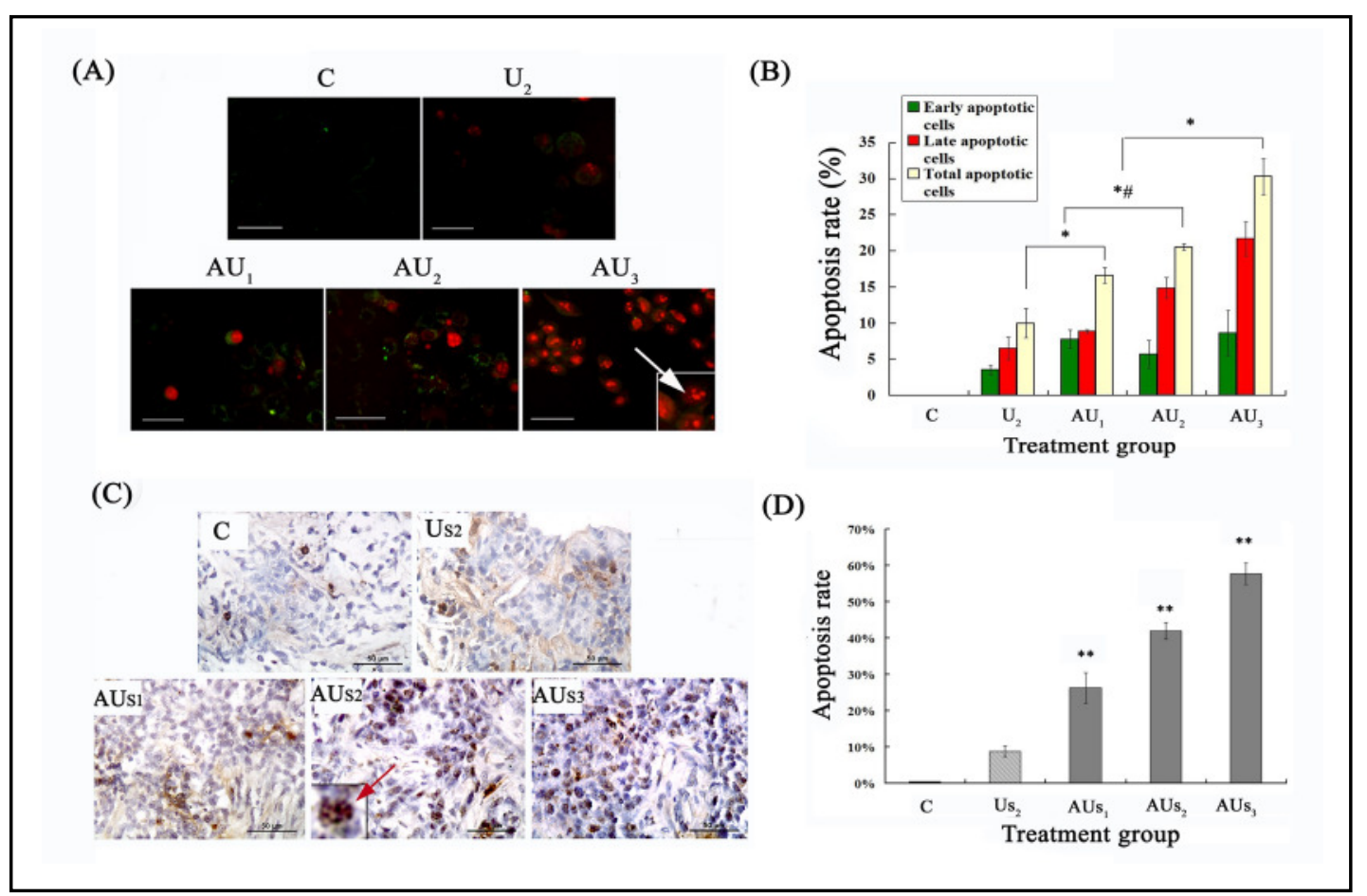

Fig. 3. Apoptosis induction with ALA-LIU or LIU in vitro and in vivo. (A) Fluorescence microscopy images of apoptotic SAS cells subjected to Annexin V-PI double staining in vitro following 4-h incubation after ALALIU treatment. Annexin V-FITC in conjunction with PI staining could distinguish early apoptotic (Annexin VFITC-positive cells yielded green fluorescence) from late apoptotic (Annexin V-positive and PI-positive cells yielded green and red fluorescence, respectively) cells. The white arrow points out the nuclear fragments of the apoptotic cells. Bar: $50 \mu \mathrm{m}$. (B) The rate of apoptosis of SAS cells as determined by FACS assay in vitro. ${ }^{*} \mathrm{p}<0.05$ and $* \# \mathrm{p}<0.01$ among groups. (C) Representative images of TUNEL staining of apoptotic cells (brown) in tumour tissue. The red arrow points out the nuclear fragments of the apoptotic cells. Bar: 50 $\mu \mathrm{m}$. (D) The cell apoptosis rate in vivo was calculated according to the formula: number of positive-stained cells/number of total cells. ${ }^{* *} \mathrm{p}<0.01$ compared with $\mathrm{C}$ or Us2 group.

was lower in the corresponding AU groups. The inhibition effect in the AU groups became stronger and the cell viability was at a minimum $4 \mathrm{~h}$ after treatment; the cell viabilities in the $\mathrm{AU}_{1}, \mathrm{AU}_{2}$, and $\mathrm{AU}_{3}$ groups were $70.5 \% \pm 2.8 \%, 60.4 \% \pm 2.7 \%$, and $54.3 \% \pm 3.1 \%$, respectively. At 6-h incubation after the treatment, cell activity increased only slightly in the AU groups, but showed a marked recovery in the U groups, indicating that ALA-LIU can persist in inhibiting cellular proliferation, with the effect strengthening with the increase in ultrasound irradiation time, similar to the in vivo results.

\section{ALA-LIU induced apoptosis of SAS cells in vivo and in vitro}

The ability of SDT to induce cellular apoptosis has been confirmed in several cell lines $[4,6,7,9]$, and is regarded as the primary mechanism by which SDT inhibits tumour growth. To analyse the pro-apoptotic effect of ALA-LIU on SAS cells, annexin V-PI double staining and FACS analysis were performed. Fluorescence microscopy images showed that ALA-LIU induced both early- and late-stage apoptosis in SAS cells, as indicated by fragmented and irregularly stained nuclei (Fig. 3A). Subsequent FACS analysis revealed that there was a significant difference $(P<0.05$ or $P<0.01)$ in the total apoptosis rate between the $U_{2}$ group and $\mathrm{AU}$ groups (Fig. $3 \mathrm{~B}$ ), including between the $\mathrm{U}_{2}$ group and $\mathrm{AU}_{1}$ group. The total apoptosis rates of the $\mathrm{AU}_{1}, \mathrm{AU}_{2}$, and $\mathrm{AU}_{3}$ groups were $16.61 \% \pm 1.13 \%, 20.53 \% \pm 0.48 \%$, and $30.31 \% \pm$ $2.48 \%$, respectively.

Subsequently, TUNEL assays were used to detect whether apoptosis could be induced by ALA-LIU in vivo. As shown in Figure 3C, ultrasound irradiation alone resulted in less apoptosis, 


\section{Cellular Physiology Cell Physiol Biochem 2012;30:321-333 \begin{tabular}{ll|l} 
and Biochemistry & $\begin{array}{l}\text { DOI: 10.1159/000339067 } \\
\text { Published online: June 25, } 2012\end{array}$ & $\begin{array}{l}\text { C 2012 S. Karger AG, Basel } \\
\text { www.karger.com/cpb }\end{array}$ \\
$\begin{array}{c}\text { Lv/Fang/Zheng et al.: Low-intensity Ultrasound and 5-aminolevulinic Acid Therapy on } \\
\text { Tongue Carcinoma }\end{array}$
\end{tabular}}

(A)

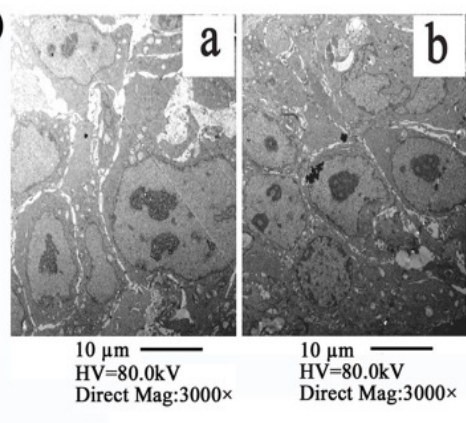

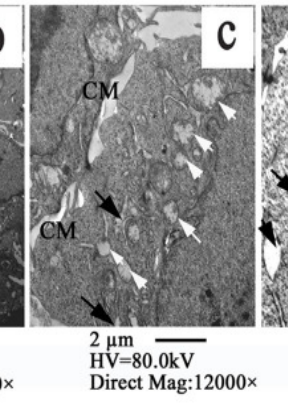

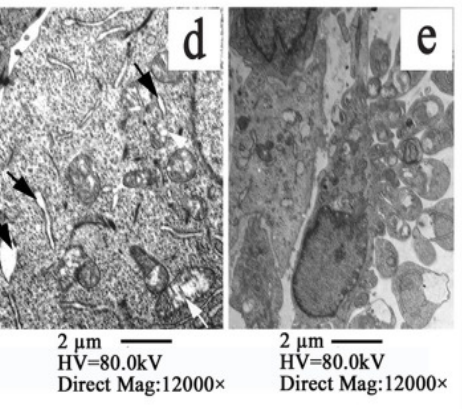

Merged

(B)

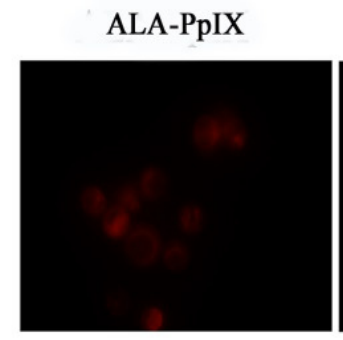

Mit-tracker
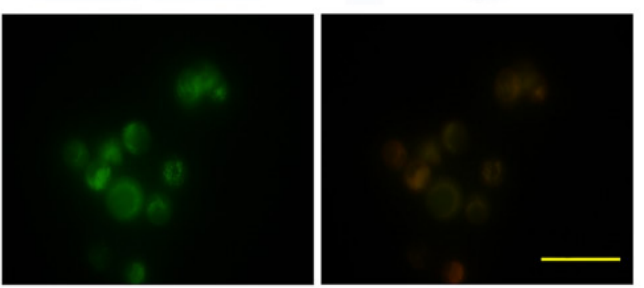

Fig. 4. Ultrastructural changes to the cells in xenograft tissue and co-localisation of ALA-induced PpIX and mitochondria in vitro. (A) Transmission electron microscopy images of SAS cells after ALA-LIU treatment. a, Tumour cells in untreated tissue. b, c, d, and e, Tumour cell in ALA-LIU treated tissues. b, Tumour cells presenting with small volume. $c$ and d, Mitochondria in the cells (white arrows) were swollen and vacuolated, at times. The endoplasmic reticulum (black arrows) expanded in the shape of cords. e, Apoptotic bodies. (B) Intracellular localisation of ALA-induced PpIX. SAS cells were co-loaded with mitochondria tracker (Rhodamine 123) and $10 \mu \mathrm{g} / \mathrm{mL}$ ALA for $4 \mathrm{~h}$. Rhodamine 123 (green panel) and endogenous PpIX (red panel) were visualised by fluorescence microscopy. Bar: $50 \mu \mathrm{m}$.

while positive particles (indicative of apoptosis) significantly increased in the corresponding AU groups. The nuclei of some tumour cells consisted of condensed chromatin, and they were fragmented, demonstrating typical features of apoptosis. The apoptosis rate increased with the number of treatments (one, two, and three) in the AUs groups, and was at least 1.7, 3.2 , and 4.5 times greater than the sonication alone group ( $\mathrm{Us}_{2}$ ), respectively (Fig. 3D). These results demonstrated that ALA-LIU effectively induced apoptosis of SAS cells in vivo, which may be the primary mechanism for the arrest of cancer cell proliferation.

\section{ALA-LIU induced cell apoptosis by the endogenous mitochondria caspase pathway}

To identify the mechanism responsible for SAS cell apoptosis, we observed ultrastructural changes of tumour cells in xenograft tissues after ALA-LIU treatment, by using a transmission electron microscope. The sizes of the tumour cells in the AU group (Fig. 4Ab) were reduced compared to the untreated group (Fig. 4Aa). Tumour cells in some areas had a large number of swollen mitochondria with fragmented or absent ridges (Fig. 4Ac). Surprisingly, it was observed that the cell nuclei and membranes showed no evident changes in these cells. The mitochondria of some cells were even vacuolated, in which the ridges had completely disappeared. Furthermore, the endoplasmic reticulum were expanded into cord-like shapes (Figs. 4Ac and 4Ad), and the nuclear chromatin was condensed and distributed around the edge of the nuclei, presenting the classical appearance of apoptotic cells. Other tumour tissues exhibited typical apoptotic bodies, as shown in Figure 4Ae. This morphological evidence showed that apoptosis induced by ALA-LIU began from the mitochondria. Prior to the occurrence of apoptosis, the organelles initially demonstrated large morphological changes, especially in the mitochondria.

Figure 4B showed that endogenous PpIX (emitting red fluorescence) was distributed in the cytoplasm, co-localised to the same region as the mitochondria (marked with green 


\section{Cellular Physiology $\quad$ Cell Physiol Biochem 2012;30:321-333 \begin{tabular}{ll|l} 
and BiOChemistry & $\begin{array}{l}\text { DOI: 10.1159/000339067 } \\
\text { Published online: June 25, } 2012\end{array}$ & $\begin{array}{l}\text { C 2012 S. Karger AG, Basel } \\
\text { www.karger.com/cpb }\end{array}$ \\
\cline { 2 - 3 } Lv/Fang/Zheng et al.: Low-intensity Ultrasound and 5-aminolevulinic Acid Therapy on
\end{tabular} Tongue Carcinoma}

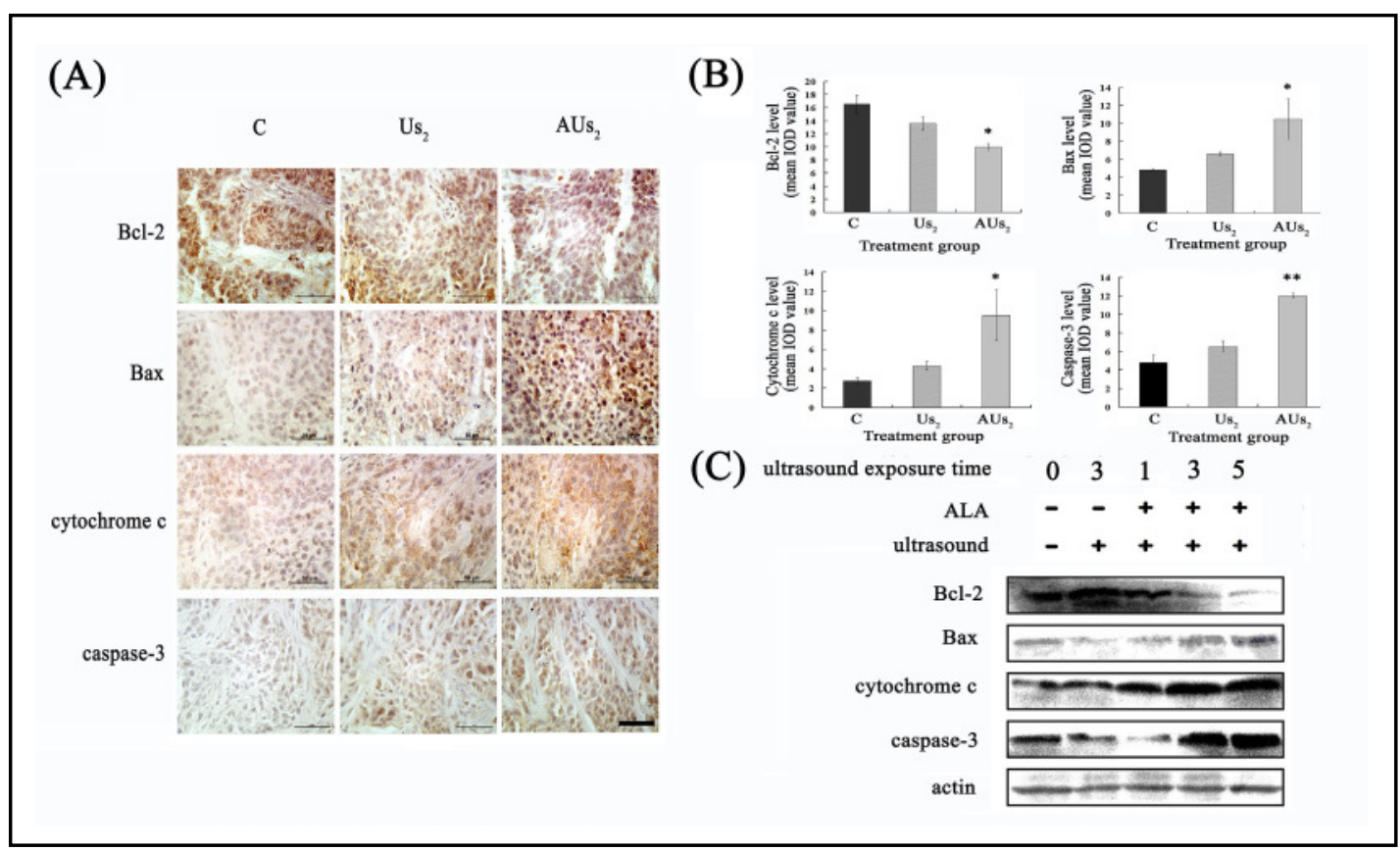

Fig. 5. Effect of ALA-LIU on mitochondrial apoptosis proteins in SAS cells in vivo and in vitro. (A) Immunohistochemical analysis in vivo showing cytoplasmic staining for Bcl-2, Bax, cytochrome-c, and caspase-3. Bar: $50 \mu \mathrm{m}$. (B) The expression level of each protein in in vivo experiment was evaluated using the mean IOD value. Data are presented as the mean \pm SD values. ${ }^{*} p<0.05$ and ${ }^{* *} p<0.01$ vs. C group. (C) Changes in the expression of cytochrome c, Bcl-2, Bax, and caspase- 3 after various treatments were analysed by immunoblotting in vitro. Increased expression of Bax, cytochrome c, and caspase- 3 and decreased expression of Bcl-2 were observed in an ultrasound-exposure time-dependent manner in ultrasound combined with ALA treatment groups.

fluorescence), implying that endogenous PpIX was converted from 5-ALA bound to the mitochondria of SAS cells. Since PpIX is sonosensitive, ultrasound irradiation implemented at this time will cause direct damage to the mitochondria, and triggered cell apoptosis.

To confirm that mitochondria play a role in the pro-apoptotic effect of ALA-LIU, we examined the expression of mitochondrion-associated apoptotic factor cytochrome c, mitochondria apoptosis regulatory factors Bcl-2 and Bax, and apoptotic executive factor caspase-3, by immunohistochemical staining and western blot analyses in vivo and in vitro. The above proteins were expressed in the cytoplasm of each group (Fig. 5A). Protein expression levels were assessed by the mean IOD value of the positively stained particles. The expression of cytochrome c, Bax, and caspase- 3 was significantly higher $(P<0.05$ or $P<$ $0.01)$, while that of Bcl-2 was lower $(P=0.03)$ in the AU group than in the control group (Fig. 5B). Similar results were achieved in the AU group in vitro by western blotting, which also revealed that the effect of ALA-LIU increases with the treatment time (Fig. 5C).

ROS play a key role in the ALA-LIU-induced mitochondria apoptosis pathway

Previous studies have shown that ultrasound combined with a sonosensitiser can raise the level of intracellular ROS in the tumour cells in vitro $[4,8,21,22]$. Therefore, we hypothesised that ALA-LIU triggers apoptosis pathway by ultrasound stimulation of the 5ALA-converted PpIX in the mitochondria to produce ROS, which damaged the sub-cellular structure. The SAS cells were incubated with DCFH-DA to determine whether treatment with ALA-LIU is associated with the generation of ROS. As shown in Figures 6A and B, ALA-LIU treatment dramatically increased ROS generation compared with the control cells and had an ultrasound irradiation time-depending manner. 


\section{Cellular Physiology $\quad$ Cell Physiol Biochem 2012;30:321-333 \begin{tabular}{ll|l} 
and BiOChemistry & $\begin{array}{l}\text { DOI: 10.1159/000339067 } \\
\text { Published online: June 25, } 2012\end{array}$ & $\begin{array}{l}\text { C 2012 S. Karger AG, Basel } \\
\text { www.karger.com/cpb }\end{array}$ \\
\cline { 2 - 3 } Lv/Fang/Zheng et al.: Low-intensity Ultrasound and 5-aminolevulinic Acid Therapy on
\end{tabular} Lv/Fang/Zheng et
Tongue Carcinoma}

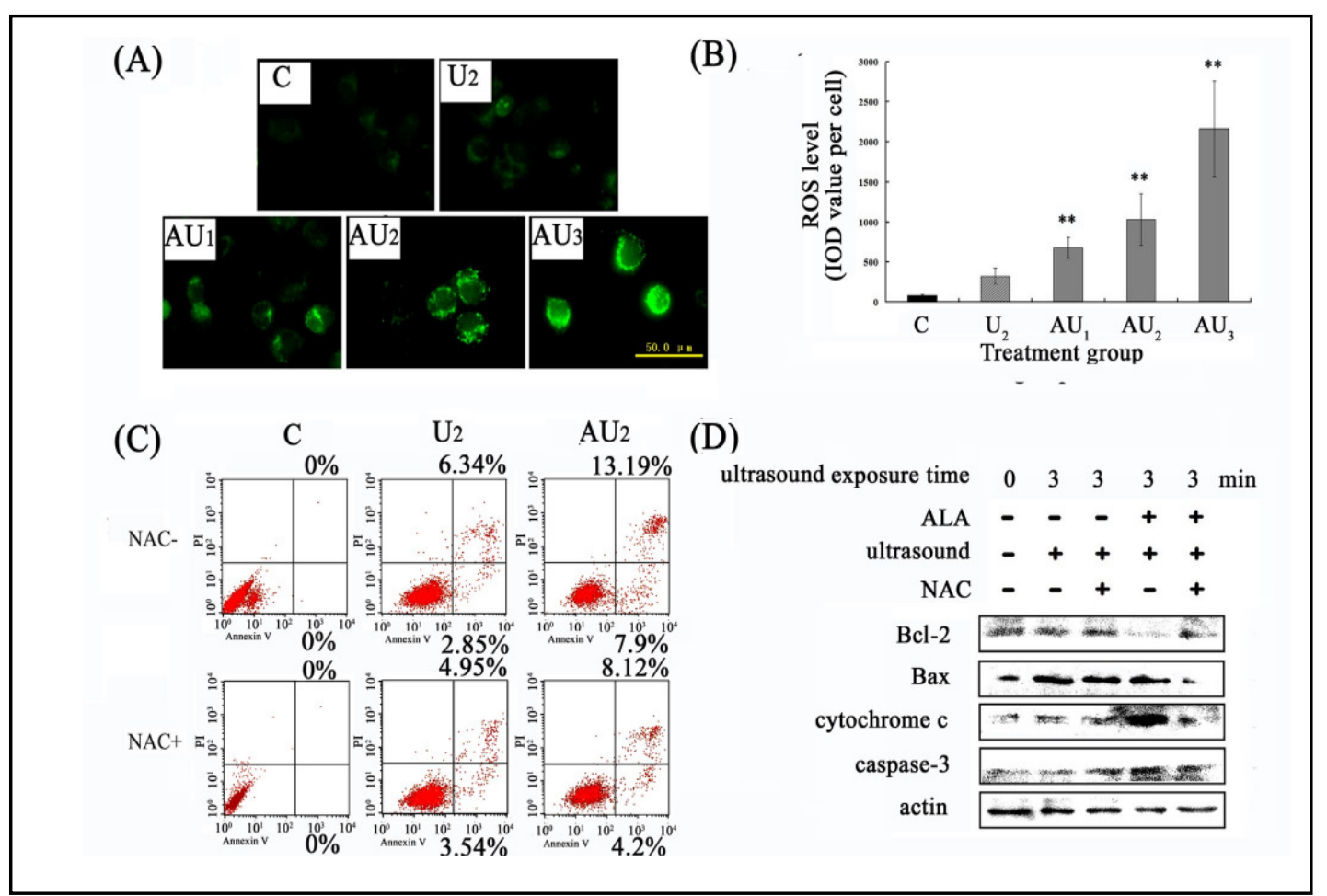

Fig. 6. Effect of reactive oxygen species (ROS) in SAS cells induced by ALA-LIU. (A) Intracellular ROS production in SAS cells were observed under the fluorescence microscope by using $2^{\prime}, 7^{\prime}$-dichlorofluorescin diacetate (DCFH-DA) staining. Light green fluorescence shows increased levels of ROS in the cytoplasm in AU groups. Bar: $50 \mu \mathrm{m}$. (B) ROS level was evaluated by fluorescence intensity analysis for each cell. Data were presented as the mean \pm SD values from three independent experiments. ${ }^{* *} p<0.01$ vs. C group. (C) Effect of ROS inhibitor (NAC) on cell apoptosis studied by FACS assay in vitro. (D) Effect of NAC on proteins activity in vitro. ALA-LIU induced the activation of Bax, cytochrome-c, and caspase- 3 and deactivation of Bcl2 , while NAC reversed the expression of the above factors induced by ALA-LIU.

Subsequently, we checked the influence of ROS on SAS cell apoptosis induced by ALALIU by using the ROS scavenger NAC. The FACS results showed that cells pre-treated with NAC showed a marked reduction in the total cell apoptosis rate of the AU group (Fig. 6C). The effects of NAC on the expression of cytochrome c, Bcl-2, Bax, and caspase-3 in the ALA-LIU treated group were further examined by western blotting. As expected, the expressions of these proteins were restored in the AU group when the cells were pre-treated with NAC (Fig. 6D). Interestingly, there were no obvious changes in protein expressions in the sonication alone group, even after pre-treatment with NAC.

Intracellular $\mathrm{Ca}^{2+}$ participated in cell apoptosis induced by ALA-LIU

The ultrastructural changes to the endoplasmic reticulum induced by ALA-LIU may result in changes in the intracellular $\mathrm{Ca}^{2+}$ concentration, and there exists a close relationship between intracellular $\mathrm{Ca}^{2+}$ concentration and ROS generation in signal transduction pathways. Therefore, the induction of apoptosis by ALA-LIU was investigated to determine a possible relationship with the increase in intracellular $\mathrm{Ca}^{2+}$ concentration. As shown in Figures 7A and $\mathrm{B}$, the treatment of SAS cells with ALA-LIU led to a dramatic increase in intracellular $\mathrm{Ca}^{2+}$ levels. The effect of NAC on the intracellular $\mathrm{Ca}^{2+}$ level in LIU- and ALA-LIU-treated SAS cells was further examined. As expected, the cells pre-treated with NAC $(10 \mathrm{mM})$ show a marked reduction in the intracellular $\mathrm{Ca}^{2+}$ levels in the AU group, which indicated that the increased $\mathrm{Ca}^{2+}$ levels induced by ALA-LIU was associated with ROS generation. 


\section{Cellular Physiology $\quad$ Cell Physiol Biochem 2012;30:321-333 \begin{tabular}{ll|l}
\cline { 3 - 3 } and Biochemistry & $\begin{array}{l}\text { DOI: 10.1159/000339067 } \\
\text { Published online: June 25, } 2012\end{array}$ & $\begin{array}{l}\text { C 2012 S. Karger AG, Basel } \\
\text { www.karger.com/cpb }\end{array}$ \\
\cline { 2 - 3 } Lv/Fang/Zheng et al.: Low-intensity Ultrasound and 5-aminolevulinic Acid Therapy on
\end{tabular} Tongue Carcinoma}

Fig. 7. Effects of ALA-LIU on intracellular $\mathrm{Ca}^{2+}$ concentration $\left[\mathrm{Ca}^{2+}\right]$ i. (A) Fluorescence microscopy images of SAS cells subjected to different treatments were loaded with Fluo-2 AM (green fluorescence). Green fluorescence indicated increased $\left[\mathrm{Ca}^{2+}\right] \mathrm{i}$ in the cytoplasm. The fluorescence intensities were restored by pre-treatment with the antioxidant NAC in AU2 group. Bar: $50 \mu \mathrm{m}$. (B) A fluorescence spectrophotometer was used to determine the level of intracellular $\left[\mathrm{Ca}^{2+}\right]$ i. Treatment of SAS cells with ALA-LIU for $4 \mathrm{~h}$ led to a marked increase in the $\left[\mathrm{Ca}^{2+}\right] \mathrm{i}$. Pre-treatment with the antioxidant NAC (10 $\mathrm{mM}$ ) significantly inhibited the increase in intracellular $\left[\mathrm{Ca}^{2+}\right] \mathrm{i}$ in AU2 group. Data were expressed as the mean \pm SD values from triplicate experiments. ${ }^{*} \mathrm{p}<0.05$ vs. C or U2 group.

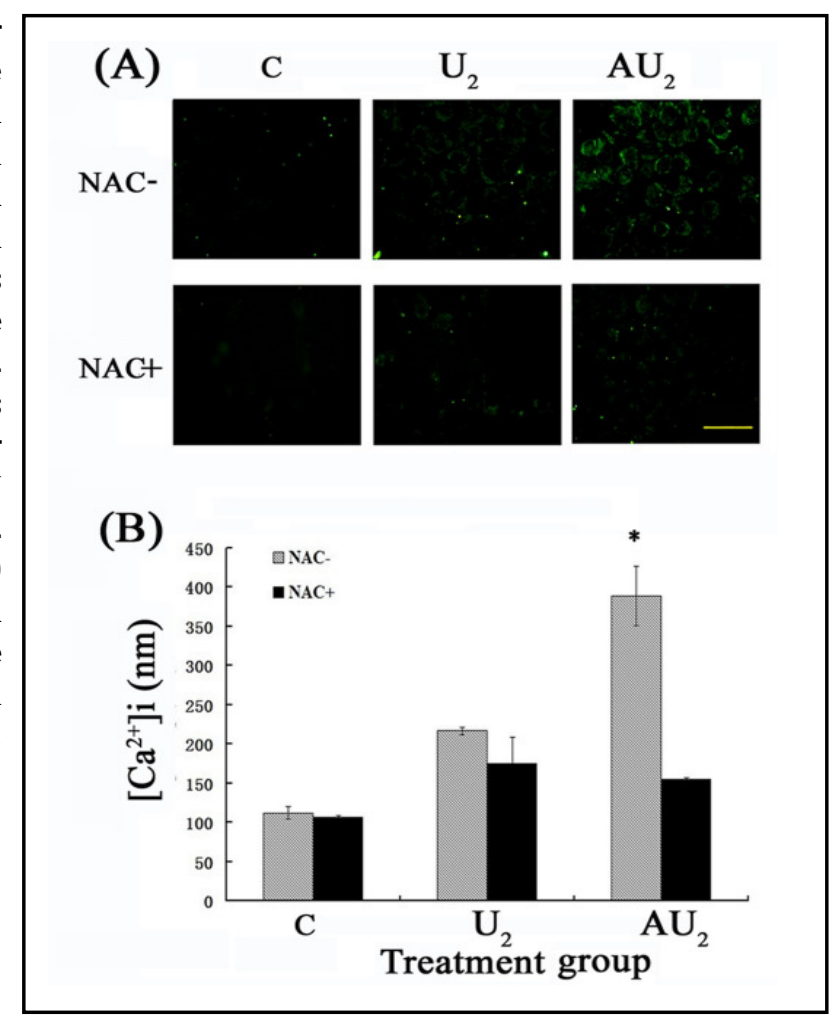

\section{Discussion}

Sonodynamic therapy, which utilises the synergistic effect of LIU and non-toxic sonosensitisation, has aroused the increasing interest of medical researchers as a noninvasive and reproducible method for cancer treatment [4, 17, 23-25]. As a photosensitising agent, 5-ALA has been examined in the context of diagnosis and treatment of PDT $[26,27]$. Since 5-ALA is not itself photosensitive, it need not be used in the dark, and may be consumed orally in a clinical setting. In the present study, we demonstrated that the combined use of 5-ALA and LIU can significantly inhibit the growth of human tongue carcinoma in vivo and in vitro. We observed that the inhibitory effect of ALA-LIU is conducted through the mitochondrial apoptosis pathway with the involvement of reactive oxygen species (ROS).

Previous studies have reported that an intensity of $3 \mathrm{~W} / \mathrm{cm}^{2}$ (or occasionally $2 \mathrm{~W} / \mathrm{cm}^{2}$ ) is the critical threshold value between low-level and high-level ultrasound. However, most investigators believe that the threshold level should be evaluated by the bio-effects produced in a specific tissue $[17,28]$. Some investigators hold the view that ultrasound promotes the growth of tissues and cells rather than supporting an inhibitory effect when the ultrasonic intensity is lower than $1 \mathrm{~W} / \mathrm{cm}^{2}[29,30]$. The LIU, combined with a sonosensitiser or SDT, is very promising technique for tumour suppression without any side effects and damage to the normal surrounding tissues. Compared to ultrasound irradiation alone, SDT can greatly suppress cellular proliferation $[2,13,31-34]$. Investigators have previously reported that different intensity of ultrasound combined with diverse sonosensitisers produced distinct biological effects on specialised cells and tissues [13,31,32,35]. In our study, the intensity of ultrasound was less than $1 \mathrm{~W} / \mathrm{cm}^{2}$ in both in vivo and in vitro experiments. We evaluated the growth inhibition and apoptosis of SAS cells induced by 5-ALA-mediated SDT, and screened the ultrasound parameters (including frequency, intensity, duty factor, duration, and treatment protocol). We confirmed that 5-ALA-based SDT effectively inhibited the proliferation of SAS cells, with a long-term inhibitory effect, compared to sonication alone (Fig. 2).

Our preliminary data in vitro (Figs. $3 \mathrm{~A}$ and $\mathrm{B}$ ) and in vivo (Figs. $3 \mathrm{C}$ and $\mathrm{D}$ ) suggested that the ALA-LIU could effectively induce SAS cell apoptosis. Furthermore, for the same 5-ALA- 


\section{Cellular Physiology $\quad$ Cell Physiol Biochem 2012;30:321-333 \begin{tabular}{ll|l} 
and Biochemistry & $\begin{array}{l}\text { DOI: 10.1159/000339067 } \\
\text { Published online: June 25, 2012 }\end{array}$ & $\begin{array}{l}\text { C 2012 S. Karger AG, Basel } \\
\text { www.karger.com/cpb }\end{array}$ \\
\cline { 2 - 3 } & Lv/Fang/Zheng et al.: Low-intensity Ultrasound and 5-aminolevulinic Acid Therapy on
\end{tabular}}

converted PpIX concentration, the apoptosis rate depends on the ultrasound irradiation time, allowing the user to regulate the degree of apoptosis by controlling ultrasound sonication time.

The ultrastructural changes in tumour cells (Fig. 4A) showed that mitochondria were the most obviously altered organelles, occurring prior to the changes observed in the nuclei and cell membranes. Therefore, we hypothesise that the apoptosis induced by ALA-LIU, which initially causes damage to the mitochondria, is distinct from the apoptosis induced by other sonosensitiser-mediated SDTs $[8,10,14,15,36]$, which initially causes damage to the cell membrane. The location of endogenous PpIX converted from 5-ALA in the mitochondria (Fig. 4B) supported this hypothesis. We found that the expression levels of the mitochondrionassociated pro-apoptosis proteins Bax, cytochrome c, and caspase- 3 were increased, while the expression level of the apoptosis inhibitory protein Bcl-2 was decreased after ALA-LIU treatment in vivo (Figs. 5A and B) and in vitro (Fig. 5C) in an ultrasound-exposure timedependent manner. Indeed, ALA-LIU-induced SAS cell death occurs via the mitochondrial caspase pathway. Our results showed that the mitochondria are the primary target of ALALIU action.

Accumulated active oxygen in tumour cells can cause oxidising reactions in biomolecules, which may disrupt the integrity of lipid membranes, enzymes, and nucleic acids. We found that ALA-LIU could increase the levels of ROS and lipid peroxide in cells [20]. In the present study, we provided more detailed evidence of ultrasound-exposure time-dependent changes in ROS induction of SAS cells (Figs. 6A and B). The free radical scavenger NAC prevented ALA-LIU-induced apoptosis and prevented changes to the mitochondrial apoptosis-related protein expression (Figs. 6C and D). These results demonstrate that reactive oxygen is the trigger for mitochondrial apoptosis pathways induced by 5-ALA-mediated SDT. It should be noted that this phenomenon did not occur when cells were treated with ultrasound alone, indicating that the pro-apoptotic mechanisms are different in LIU alone, compared with ALA-LIU treatments.

Apoptosis induced by ultrasonic irradiation was presumed to due to increased intracellular $\mathrm{Ca}^{2+}$ levels $[37,38]$. Recent studies also revealed a relationship between SDT and intracellular $\mathrm{Ca}^{2+}[22,36,39]$. Our results showed that ALA-LIU treatment significantly increased the concentration of intracellular $\mathrm{Ca}^{2+}$, which was inhibited by a scavenger of reactive oxygen, indicating that changes in the intracellular $\mathrm{Ca}^{2+}$ concentration, also initiated by ROS, are not a separate cause of, but the other major contributor to, apoptosis.

In summary, we report strong evidence suggesting that ALA-LIU treatment inhibits SAS cell proliferation in vivo and in vitro, in part by targeting the mitochondria, through mitochondrion-mediated apoptosis signalling pathways, and that both apoptosis and change in intracellular $\mathrm{Ca}^{2+}$ concentration are closely related to ROS concentration. The encouraging results observed in SAS cells and animal models demonstrate the great potential of 5-ALAmediated SDT for treating human tongue squamous carcinoma.

\section{Abbreviations}

SDT (Sonodynamic therapy); 5-ALA (5-aminolevulinic acid); PpIX (protoporphyrin IX); HIFU (high-intensity focused ultrasound); LIU (low intensity ultrasound); ROS (reactive oxygen species); DCF-DA (2,7-Dichlorofluorescein diacetate); NAC (N-acetylcysteine); IOD (integrated optical density).

\section{Acknowledgements}

This research was supported by Heilongjiang Province Doctoral Innovation Foundation (YJSCX2011-322HLJ), Heilongjiang Province Postdoctoral Science Foundation (No LRB-05-153) and the Harbin City Bureau of Science and Technology Key project fund (2009AA3BS131). 


\section{Cellular Physiology Cell Physiol Biochem 2012;30:321-333

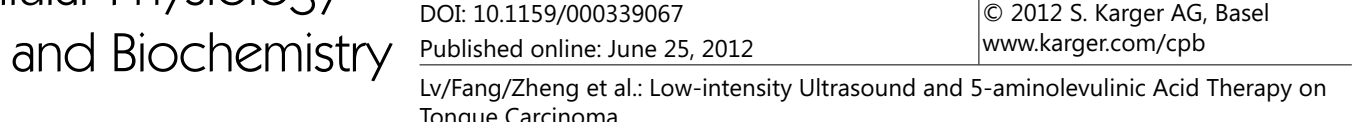

\section{Conflict of Interest}

None declared.

\section{References}

1 Bello IO, Soini Y, Salo T: Prognostic evaluation of oral tongue cancer: Means, markers and perspectives (i). Oral Oncol 2010;46:630-635.

2 Liu Q Wang X, Wang P, Xiao L: Sonodynamic antitumor effect of protoporphyrin ix disodium salt on s180 solid tumor. Chemotherapy 2007;53:429-436.

3 Yumita N, Okuyama N, Sasaki K, Umemura S: Sonodynamic therapy on chemically induced mammary tumor: Pharmacokinetics, tissue distribution and sonodynamically induced antitumor effect of gallium-porphyrin complex atx-70. Cancer Chemother Pharmacol 2007;60:891-897.

4 Wang XB, Liu QH, Mi N, Wang P, Tang W, Zhao XH, Li XJ: Sonodynamically induced apoptosis by protoporphyrin ix on hepatoma-22 cells in vitro. Ultrasound Med Biol 2010;36:667-676.

5 Quan-hong L, Shi-hui S, Ya-ping X, Hao Q, Jin-xuan Z, Yao-hui R, Meng L, Pan W: Synergistic anti-tumor effect of ultrasound and hematoporphyrin on sarcoma180 cells with special reference to the changes of morphology and cytochrome oxidase activity of tumor cells. J Exp Clin Cancer Res 2004;23:333-341.

6 Li JH, Song DY, Xu YG, Huang Z, Yue W: In vitro study of haematoporphyrin monomethyl ether-mediated sonodynamic effects on c6 glioma cells. Neurol Sci 2008;29:229-235.

7 Li Y, Wang P, Zhao P, Zhu S, Wang X, Liu Q: Apoptosis induced by sonodynamic treatment by protoporphyrin ix on mda-mb-231 cells. Ultrasonics 2012;52:490-496.

8 Yumita N, Okudaira K, Momose Y, Umemura S: Sonodynamically induced apoptosis and active oxygen generation by gallium-porphyrin complex, atx-70. Cancer Chemother Pharmacol 2010;66:1071-1078.

9 Feril LB, Jr., Kondo T, Cui ZG, Tabuchi Y, Zhao QL, Ando H, Misaki T, Yoshikawa H, Umemura S: Apoptosis induced by the sonomechanical effects of low intensity pulsed ultrasound in a human leukemia cell line. Cancer Lett 2005;221:145-152.

10 Tang W, Liu Q, Wang X, Wang P, Cao B, Mi N, Zhang J: Involvement of caspase 8 in apoptosis induced by ultrasound-activated hematoporphyrin in sarcoma 180 cells in vitro. J Ultrasound Med 2008;27:645-656.

11 Wang XB, Liu QH, Wang P, Zhang K, Tang W, Wang BL: Enhancement of apoptosis by sonodynamic therapy with protoporphyrin ix in isolate sarcoma. Cancer Biother Radiopharm 2008;23:238-246.

12 Tang W, Liu Q, Zhang J, Cao B, Zhao P, Qin X: In vitro activation of mitochondria-caspase signaling pathway in sonodynamic therapy-induced apoptosis in sarcoma 180 cells. Ultrasonics 2010;50:567-576.

13 Wang XB, Liu QH, Wang P, Tang W, Hao Q: Study of cell killing effect on s180 by ultrasound activating protoporphyrin ix. Ultrasonics 2008;48:135-140.

14 Wang X, Wang Y, Wang P, Cheng X, Liu Q: Sonodynamically induced anti-tumor effect with protoporphyrin ix on hepatoma-22 solid tumor. Ultrasonics 2011;51:539-546.

15 Wang X, Wang P, Tong W, Liu Q: Comparison of pharmacokinetics, intracellular localizations and sonodynamic efficacy of endogenous and exogenous protoporphyrin ix in sarcoma 180 cells. Ultrasonics 2010;50:803810.

16 Leslie TA, Kennedy JE: High intensity focused ultrasound in the treatment of abdominal and gynaecological diseases. Int J Hyperthermia 2007;23:173-182.

17 Yu T, Wang Z, Mason TJ: A review of research into the uses of low level ultrasound in cancer therapy. Ultrason Sonochem 2004;11:95-103.

18 Hasanzadeh H, Mokhtari-Dizaji M, Bathaie SZ, Hassan ZM, Nilchiani V, Goudarzi H: Enhancement and control of acoustic cavitation yield by low-level dual frequency sonication: A subharmonic analysis. Ultrason Sonochem 2011;18:394-400.

19 Wang X, Liu Q, Wang Z, Wang P, Hao Q, Li C: Bioeffects of low-energy continuous ultrasound on isolated sarcoma 180 cells. Chemotherapy 2009;55:253-261.

20 Song W, Cui H, Zhang R, Zheng J, Cao W: Apoptosis of sas cells induced by sonodynamic therapy using 5aminolevulinic acid sonosensitizer. Anticancer Res 2011;31:39-45. 


\section{Cellular Physiology Cell Physiol Biochem 2012;30:321-333 \begin{tabular}{ll|l} 
and Biochemistry & DOI: 10.1159/000339067 & $\begin{array}{l}\text { C 2012 S. Karger AG, Basel } \\
\text { www.karger.com/cpb }\end{array}$ \\
\cline { 2 - 3 } & Lv/Fang/Zhed online: June 25, 2012 & Lval.: Low-intensity Ultrasound and 5-aminolevulinic Acid Therapy on
\end{tabular}}

21 Indran IR, Tufo G, Pervaiz S, Brenner C: Recent advances in apoptosis, mitochondria and drug resistance in cancer cells. Biochim Biophys Acta 2011;1807:735-745.

22 Tian Z, Quan X, Leung AW, Xiang J, Xu C: Hematoporphyrin monomethyl ether enhances the killing of ultrasound on osteosarcoma cells involving intracellular reactive oxygen species and calcium ion elevation. Integr Cancer Ther 2010;9:365-369.

23 Shibaguchi H, Tsuru H, Kuroki M: Sonodynamic cancer therapy: A non-invasive and repeatable approach using low-intensity ultrasound with a sonosensitizer. Anticancer Res 2011;31:2425-2429.

24 Barati AH, Mokhtari-Dizaji M: Ultrasound dose fractionation in sonodynamic therapy. Ultrasound Med Biol 2010;36:880-887.

25 Kuroki M, Hachimine K, Abe H, Shibaguchi H, Maekawa S, Yanagisawa J, Kinugasa T, Tanaka T, Yamashita Y: Sonodynamic therapy of cancer using novel sonosensitizers. Anticancer Res 2007;27:3673-3677.

26 Sasaki K, Watanabe M, Tanaka T: Biosynthesis, biotechnological production and applications of 5aminolevulinic acid. Appl Microbiol Biotechnol 2002;58:23-29.

27 Zhao B, He YY: Recent advances in the prevention and treatment of skin cancer using photodynamic therapy. Expert Rev Anticancer Ther 2010;10:1797-1809.

28 Ahmadi F, McLoughlin IV, Chauhan S, Ter-Haar G: Bio-effects and safety of low-intensity, low-frequency ultrasonic exposure. Prog Biophys Mol Biol 2012

29 Takeuchi R, Ryo A, Komitsu N, Mikuni-Takagaki Y, Fukui A, Takagi Y, Shiraishi T, Morishita S, Yamazaki Y, Kumagai K, Aoki I, Saito T: Low-intensity pulsed ultrasound activates the phosphatidylinositol 3 kinase/akt pathway and stimulates the growth of chondrocytes in three-dimensional cultures: A basic science study. Arthritis Res Ther 2008;10:R77.

30 Tsuang YH, Liao LW, Chao YH, Sun JS, Cheng CK, Chen MH, Weng PW: Effects of low intensity pulsed ultrasound on rat schwann cells metabolism. Artif Organs 2011;35:373-383.

31 Liu Q Li X, Xiao L, Wang P, Wang X, Tang W: Sonodynamically induced antitumor effect of hematoporphyrin on hepatoma 22. Ultrason Sonochem 2008;15:943-948.

32 Xiaohuai W, Lewis TJ, Mitchell D: The tumoricidal effect of sonodynamic therapy (sdt) on s-180 sarcoma in mice. Integr Cancer Ther 2008;7:96-102.

33 Harada Y, Ogawa K, Irie Y, Endo H, Feril LB, Jr., Uemura T, Tachibana K: Ultrasound activation of tio2 in melanoma tumors. J Control Release 2011;149:190-195.

34 Wang $\mathrm{P}, \mathrm{Xu} \mathrm{CS}, \mathrm{Xu} \mathrm{J}$, Wang X, Leung AW: Hypocrellin b enhances ultrasound-induced cell death of nasopharyngeal carcinoma cells. Ultrasound Med Biol 2010;36:336-342.

35 Miyoshi N, Igarashi T, Riesz P: Evidence against singlet oxygen formation by sonolysis of aqueous oxygensaturated solutions of hematoporphyrin and rose bengal. The mechanism of sonodynamic therapy. Ultrason Sonochem 2000;7:121-124.

36 Jin H, Zhong X, Wang Z, Huang X, Ye H, Ma S, Chen Y, Cai J: Sonodynamic effects of hematoporphyrin monomethyl ether on cne-2 cells detected by atomic force microscopy. J Cell Biochem 2011;112:169-178.

37 Hassan MA, Campbell P, Kondo T: The role of $\mathrm{Ca}^{2+}$ in ultrasound-elicited bioeffects: Progress, perspectives and prospects. Drug Discov Today 2010;15:892-906.

38 Hutcheson JD, Schlicher RK, Hicks HK, Prausnitz MR: Saving cells from ultrasound-induced apoptosis: Quantification of cell death and uptake following sonication and effects of targeted calcium chelation. Ultrasound Med Biol 2010;36:1008-1021.

39 Li JH, Yue W, Huang Z, Chen ZQ Zhan Q, Ren FB, Liu JY, Fu SB: Calcium overload induces c6 rat glioma cell apoptosis in sonodynamic therapy. Int J Radiat Biol 2011;87:1061-1066. 